\title{
FACTORS CONTRIBUTING TO FREEWAY CRASHES AND COLLISIONS: SOME MEASURES AND FINDINGS ALONG TDM IMPLEMENTATION
}

Freeway plays an important role in economic and social development, especially for developing countries such as China, which is also an essential issue in TDM strategy. Therefore, proper infrastructure maintenance and management are significantly necessary. Currently, accident related factors and exact effect degree are mostly conducted by human observation. Automated operation would substantially improve the processing speed and accuracy of the key processing tasks, factor detection, classification and degreeing, since the human observation of the large amount of data is tedious, error-prone and time-consuming. 2003 2005 accident data is surveyed from two typical freeways, Jiqing and Dongqing, and then rear-end collision accident is divided into two patterns, namely rear-collision and stationary object collision. PCA (Principal Component Analysis) is induced to identify the effect level of different factors on above mentioned two types of collisions, which reduces the dimension of the image as well as keeping the most important features, and significant effect factors are identified by charting analysis and clustering research. The final investigation result indicates that fatigue driving, over-speeding, environmental factor, unsafe following, truck overload, and trunk driving, over-speeding, overcrowd, fatigue driving illegal overtaking, are main effect factors on rear collisions and stationary vehicle collisions, respectively. Preliminary experimental result presented in the following demonstrates that such a proposed method has potential to solve the identification and classification problem of factors contributing to freeway crashes and collisions.

Keyword: freeway; TDM strategy; rear-end collision; principal component analysis; effect factor

Nowadays, automobiles are pouring into general urban families and becoming a need for enjoying the convenience and shortcut of modern life directly brought by technological development. However, severe social problems, such as heavy traffic congestion, environmental pollution, and traffic accidents, etc, have become one of the central and heated issues, concomitancy with the increase of automobile, among which traffic accident especially attracts the world's attention. In China, for instance, it was officially announced that more than one million people lost lives in traffic accidents in 2003 , in which random rear-end and side-wiping collisions, induced by too small vehicle following gap and brake distance, cover about one-third of the total amount.

To cope with this problem, a program on Intelligent Transportation System (ITS) has been proposed to increase road efficiency and decrease the negative effect of accident-related factors and other countermeasures, both administrative and technological, have also been adopted to investigate the rules and probability of traffic accidents [1,2]. During the research, rear-end collision is considered as the main accident pattern on freeway and its occurrence regulation is considered to be a key idea affecting investigation result and result implication, specially rear-end and side-wiping collision $[3,4]$.
Taking the 2003 2005 freeway accident data surveyed from Jiqing Freeway and Dongqing Freeway into consideration, rear-end collision accident is divided into two patterns, including rear-collision and stationary object collision. Principal component analysis (PCA) is induced to identify the effect level of different factors on two types of rear-end collisions. Then, significant effect factors are detected and chosen by charting analysis and clustering research. Such a research would have a significant effect on the occurrence of stationary object collision, which provides a reference to Freeway management departments for TDM strategy.

\section{Classification of Rear-end Collision Accidents on Freeway}

According to accident pattern [5], freeway rear-end collision accidents are divided into two types, including rear collision, characterized by the collision between the head of following vehicle and the rear of leading vehicle. The other is stationary object collision, which occurs between the head of following vehicle and the rear of stationary vehicle parking around the road.

\footnotetext{
* Ren Xian-qiang ${ }^{1,2}$, Liu Jian-yi ${ }^{1}$

${ }^{1}$ School of Business Administration, Jiangsu University, China, Email: zhanglip0503@163.com

${ }^{2}$ School of Transportation and Vehicle Engineering, Shandong University of Technology, China,
} 
Based on above definition, accident surveyed from Jiqing Freeway and Dongqing Freeway ranging from 2003 to 2005 is classified into two types, as listed in Table 1.

Four indicators of rear-end accident pattern distribution

Table 1

\begin{tabular}{|l|l|c|c|c|c|}
\hline Freeway & $\begin{array}{c}\text { Accident } \\
\text { type }\end{array}$ & $\begin{array}{c}\text { Accident } \\
\text { Count } \\
\text { (Times) }\end{array}$ & $\begin{array}{c}\text { Death } \\
\text { (Persons) }\end{array}$ & $\begin{array}{c}\text { Injury } \\
\text { (Persons) }\end{array}$ & $\begin{array}{c}\text { Economic } \\
\text { loss ( } \times 10^{4} \\
\text { Yuan RMB }\end{array}$ \\
\hline \multirow{2}{*}{ Diqing } & $\begin{array}{l}\text { Rear-end } \\
\text { collision }\end{array}$ & 45 & 34 & 43 & 93.66 \\
\cline { 2 - 6 } & $\begin{array}{l}\text { Stationary } \\
\text { vehicle } \\
\text { collision }\end{array}$ & 7 & 3 & 9 & 5.75 \\
\hline \multirow{2}{*}{ Dongqing } & $\begin{array}{l}\text { Rear-end } \\
\text { collision }\end{array}$ & 53 & 41 & 33 & 142.68 \\
\cline { 2 - 6 } & $\begin{array}{l}\text { Stationary } \\
\text { vehicle } \\
\text { collision }\end{array}$ & 8 & 2 & 5 & 9.39 \\
\hline
\end{tabular}

Equivalent number of accidents is introduced to analyze the seriousness of different patterns of freeway accidents.

$$
E R_{i}=K_{1} F_{i}+K_{2} J_{i}+R_{i}
$$

where $E R_{i}$ is the equivalent number of the $i^{\text {th }}$ rear-end accident. $K_{1}$ is the weight of dead persons in the ith rear-end accident. $K_{2}$ is the weight of injured persons in the $i^{\text {th }}$ rear-end accident. $F_{i}$ is the statistical number of dead persons in the $i^{\text {th }}$ rear-end accident. $J_{i}$ is the statistical number of injured persons in the ith rear-end accident. $R_{i}$ is the accident number of the $i^{\text {th }}$ rear-end accident.

For the sake of simplicity [6], the weight $k_{1}$ of dead person is considered as 2.0 and the corresponding injured $k_{2}$ as 1.5 . From Table 1, the equivalent numbers of each rear-end accident pattern on Jiqing Freeway are obtained as $E R_{1}=177.5, E R_{2}=26.5$ and the same result for Dongqing Freeway is $E R_{1}=184.5, E R_{2}=19.5$. Therefore, rear-end collision is the main accident pattern among freeway accidents.

\section{Process of Principal Component Analysis Method}

To distinguish the effect degree of above-mentioned factors for Freeway rear-end collision [7], principal components analysis method, which is a kind of statistical analysis method transferring a few of indicators into some main indictors, is used to analyze the effect degree. According to its working theory, the calculation process is divided into the following six steps [8].

(1) Data Preparation

The statistical accident data is recorded as:

$$
X=\left[\begin{array}{c}
X_{1} \\
X_{2} \\
\vdots \\
X_{3}
\end{array}\right]=\left[\begin{array}{cccc}
x_{11} & x_{12} & \cdots & x_{1 p} \\
x_{21} & x_{22} & \cdots & x_{2 p} \\
\vdots & \vdots & & \vdots \\
x_{n 1} & x_{n 2} & \cdots & x_{n p}
\end{array}\right]
$$

(2) Data standardization

Accident data is standardized by $\mathrm{Z}$ - score as:

$$
x_{i j}^{*}=\left(x_{i j}-\bar{x}_{j}\right) / \sigma_{j} \quad(i=1,2, \ldots \text { and } j \Rightarrow 1,2, \ldots p)
$$

where:

$$
\begin{aligned}
& \bar{x}_{j}=\sum_{t=1}^{n} x_{i j} / n \quad(t=1,2, \ldots n) \\
& \sigma_{j}^{2}=\frac{1}{n-1} \sum_{t=1}^{n}\left(x_{t i}-\bar{x}_{j}\right)^{2} \quad(t=1,2, \ldots n)
\end{aligned}
$$

(3) Correlation coefficient matrix $R$ determination

$$
R=\left(r_{i j}\right)_{p \times p}
$$

where

$$
r_{i j}=\frac{1}{n-1} \sum_{t=1}^{n} x_{t i}^{*} \square x_{t j}^{*}(i=1,2, \ldots, \text { and } j \Rightarrow 1,2, \ldots, p)(7)
$$

(4) Eigenvalues and eigenvectors of $R$

If eigenvalues comply with $\lambda_{1} \geq \lambda_{2} \geq \ldots \geq \lambda_{p} \geq 0 \succeq a_{1}, a_{2}$, ..., $p$ is the corresponding Orthogonal unit eigenvector, then the $i^{\text {th }}$ $\mathrm{PCA}$ of vector $\mathrm{X}$ is defined as:

$$
Z_{i}=a_{i}^{t} X \quad(i=1,2, \ldots, n)
$$

where $Z_{1}$ is named as the first principal component of investigated vector.

(5) Contribution rate of PCA

$$
G(m)=\sum_{i=1}^{m} \lambda_{i} / \sum_{i=1}^{p} \lambda_{i} \quad(i=1,2, \text { É }, n)
$$

(6) Result analysis

According to the analysis result, accident causes could be investigated.

\section{Principal Components Analysis of Accident Effect Factor}

The purpose of analyzing the effect factors is to make the quantitative analysis of the relation between each factor and the occurrence probability of rear-end collision and detect the main factors, which will provide a research basis [9].

\subsection{Rear-end accidents}

Four indictors of rear-end collision on Jiqing Freeway and Dongqing Freeway are surveyed over the time of 2003-2005, the result is obtained by principal components analysis method as the following.

(1) Eigenvalues and eigenvectors

$\lambda_{1}=3.6232, \lambda_{2}=0.1837, \lambda_{3}=0.0627, \lambda_{4}=0.0329$ 
The eigenvector of $\lambda_{1}$ is $Z_{1}=(0.5121 \square 0.5246 \square 0.4678 \square$ $0.4905)$.

(2) Contribution rate of PCA

Suppose $m=1$, then the contribution rate of PCA can be calculated by Eq (9):

$$
G(1)=\sum_{i=1}^{m} \lambda_{i} / \sum_{i=1}^{p} \lambda_{i}=0.9189>80 \%
$$

The result is more than 80 percent and indicates the feasibility of characterizing the four indicators with a comprehensive one.

\section{(3) Analysis result}

The effect force of each factor can be judged by Eq (8):

$$
Z_{1}=0.5121 X_{1}+0.5246 X_{2}+0.4678 X_{3}+0.4905 X_{4}
$$

where $X_{i}$ is the standardized accident data as listed in Table 2 .

Four standardized indicators and evaluation Table 2 data of effect factors

\begin{tabular}{|c|l|c|c|c|c|c|}
\hline ID & Effect factor & $\begin{array}{c}\text { Accident } \\
\text { count } \\
\left(\mathrm{X}_{1}\right)\end{array}$ & $\begin{array}{c}\text { Dead } \\
\text { toll } \\
\left(\mathrm{X}_{2}\right)\end{array}$ & $\begin{array}{c}\text { Injuries } \\
\left(\mathrm{X}_{3}\right)\end{array}$ & $\begin{array}{c}\text { Losses } \\
\left(\mathrm{X}_{4}\right)\end{array}$ & $\begin{array}{c}\text { Evalua- } \\
\text { tion } \\
\left(\mathrm{Z}_{1}\right)\end{array}$ \\
\hline 1 & Over-speeding & 1.9544 & 1.5643 & 2.0604 & 0.8278 & 3.2088 \\
\hline 2 & Drunk & -0.5113 & -0.6187 & -0.6953 & -0.5824 & -1.2033 \\
\hline 3 & Fatigue & 1.7399 & 2.2537 & 1.8399 & 2.6069 & 4.2116 \\
\hline 4 & $\begin{array}{l}\text { Truck } \\
\text { overload }\end{array}$ & -0.1897 & -0.0442 & 0.2968 & 0.7024 & 0.3725 \\
\hline 5 & Overcrowd & -0.5113 & -0.5038 & -0.5873 & -0.6766 & -1.1365 \\
\hline 6 & $\begin{array}{l}\text { Illegal } \\
\text { overtaking }\end{array}$ & -0.6185 & -0.6187 & -0.5851 & -0.5711 & -1.1938 \\
\hline 7 & $\begin{array}{l}\text { Illegal } \\
\text { parking }\end{array}$ & -0.8329 & -0.6187 & -0.6953 & -0.7029 & -1.4230 \\
\hline 8 & $\begin{array}{l}\text { Unsafe } \\
\text { following }\end{array}$ & 0.5608 & 0.1856 & 0.0763 & 0.3245 & 0.5730 \\
\hline 9 & $\begin{array}{l}\text { Illegal lane- } \\
\text { change }\end{array}$ & -0.61848 & -0.6187 & -0.5851 & -0.6615 & -1.2415 \\
\hline 10 & $\begin{array}{l}\text { Brake } \\
\text { misconduct }\end{array}$ & -0.2969 & -0.5038 & -0.3646 & 0.0091 & -0.5826 \\
\hline 11 & Vehicle effect & 0.7752 & 0.7601 & 0.5172 & -0.0116 & 1.0314 \\
\hline 12 & Pavement & -0.8329 & -0.6187 & -0.6953 & -0.7029 & -1.4229 \\
\hline 13 & $\begin{array}{l}\text { Environmen- } \\
\text { tal factor }\end{array}$ & -0.6185 & -0.6187 & -0.5851 & -0.5617 & -1.1938 \\
\hline
\end{tabular}

\subsection{Effect factors of stationary vehicle collision}

Four indictors of stationary vehicle collision on Jiqing Freeway and Dongqing Freeway are surveyed over the time of 2003-2005, and the result is obtained by principal components analysis method as

(1) Eigenvalues and eigenvectors $\lambda_{1}=3.6050, \lambda_{2}=0.3904, \lambda_{3}=0.0045, \lambda_{4}=0.0002$

The eigenvector of $\lambda_{1}$ is $Z_{1}=(0.5265 \square 0.4505 \square 0.4965 \square$ $0.5228)$

(2) Contribution rate of PCA

Supposing $m=1$, then the contribution rate of PCA can be calculated by $\mathrm{Eq}(9)$

$$
G(1)=\sum_{i=1}^{m} \lambda_{i} / \sum_{i=1}^{p} \lambda_{i}=0.9012>80 \%
$$

The result is more than $80 \%$ and indicates the feasibility of characterizing the four indicators with a comprehensive one.

(3) Analysis result

The effect force of each factor can be judged by Eq (8) as

$$
Z_{1}=0.5265 X_{1}+0.4505 X_{2}+0.4965 X_{3}+0.5228 X_{4}
$$

where $X_{i}$ is the standardized accident data as listed in Table 3 .

Four standardized indicators and evaluation

Table 3 data of effect factors

\begin{tabular}{|c|l|c|c|c|c|c|}
\hline ID & Effect factor & $\begin{array}{c}\text { Accident } \\
\text { count } \\
\left(\mathrm{X}_{1}\right)\end{array}$ & $\begin{array}{c}\text { Dead } \\
\text { toll } \\
\left(\mathrm{X}_{2}\right)\end{array}$ & $\begin{array}{c}\text { Injuries } \\
\left(\mathrm{X}_{3}\right)\end{array}$ & $\begin{array}{c}\text { Losses } \\
\left(\mathrm{X}_{4}\right)\end{array}$ & $\begin{array}{c}\text { Evalua- } \\
\text { tion } \\
\left(\mathrm{Z}_{1}\right)\end{array}$ \\
\hline 1 & Over-speeding & 2.6524 & 1.3293 & 3.0077 & 2.8108 & 4.9582 \\
\hline 2 & Drunk & -0.4443 & -0.4921 & -0.3454 & -0.4229 & -0.8483 \\
\hline 3 & Fatigue & 1.3262 & 2.2387 & 0.7734 & 1.0829 & 2.6570 \\
\hline 4 & $\begin{array}{l}\text { Truck } \\
\text { overload }\end{array}$ & -0.4412 & -0.4887 & -0.3431 & -0.4201 & -0.8424 \\
\hline 5 & Overcrowd & -0.4372 & -0.4843 & -0.3399 & -0.4163 & -0.8348 \\
\hline 6 & $\begin{array}{l}\text { Illegal } \\
\text { overtaking }\end{array}$ & -0.4474 & -0.4956 & -0.3478 & -0.4259 & -0.8542 \\
\hline 7 & $\begin{array}{l}\text { Illegal } \\
\text { parking }\end{array}$ & 0.4315 & 1.2973 & -0.3354 & 0.3074 & 0.8058 \\
\hline 8 & $\begin{array}{l}\text { Unsafe } \\
\text { following }\end{array}$ & -0.3974 & -0.4402 & -0.3090 & -0.3783 & -0.7588 \\
\hline 9 & $\begin{array}{l}\text { Illegal lane- } \\
\text { change }\end{array}$ & -0.4461 & -0.4941 & -0.3468 & -0.42468 & -0.8517 \\
\hline 10 & $\begin{array}{l}\text { Brake } \\
\text { misconduct }\end{array}$ & -0.4279 & -0.4741 & -0.3327 & -0.4074 & -0.8171 \\
\hline 11 & Vehicle effect & -0.4292 & -0.4755 & -0.3337 & -0.4087 & -0.8196 \\
\hline 12 & Pavement & -0.4871 & -0.5395 & -0.3787 & -0.4637 & -0.9301 \\
\hline 13 & $\begin{array}{l}\text { Environmen- } \\
\text { tal factor }\end{array}$ & -0.4142 & -0.4588 & -0.3221 & -0.3944 & -0.7909 \\
\hline
\end{tabular}

\section{Effect Factor Choice}

The purpose of analyzing the effect factors is to make the quantitative analysis of effect factors on rear-end collisions with the calculation result of evaluation indicators, which will provide the 
basis for the relation judgment between each factor and the occurrence probability of rear-end collision.

\subsection{Effect factor of rear-end accidents}

Using charts and cluster analysis methods to choose the effect factors behind the accident, then the main effect factors can be selected.

\section{(1) Chart method}

The chart is a more commonly used method with the simple, direct, easy to understand features. Effect factors acquired by principal component analysis are sorted according to size, then the evaluation index chart is drawn, as shown in Fig. 1.

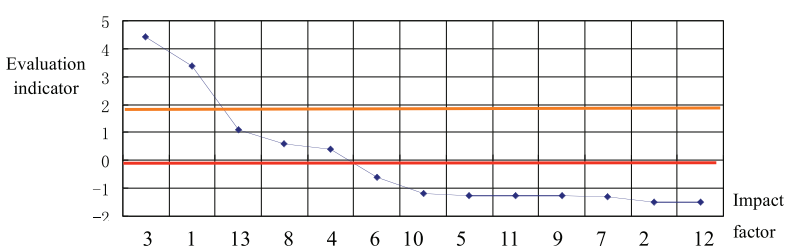

Fig. 1 Effect factor evaluation on rear-end collision on freeway

From Fig. 1, design elements are divided into three types according to the curve trend, then 0 and 2 are chosen as thresholds.

(2) Clustering analysis

The basic idea of clustering analysis is to classify each research object in a category and combine the two that are most similar with each other, then calculate the distance and similarity between a new category and other categories. This process continues until all objects are classified as a category.

With SPSS, Fig. 3 shows the result of clustering analysis.

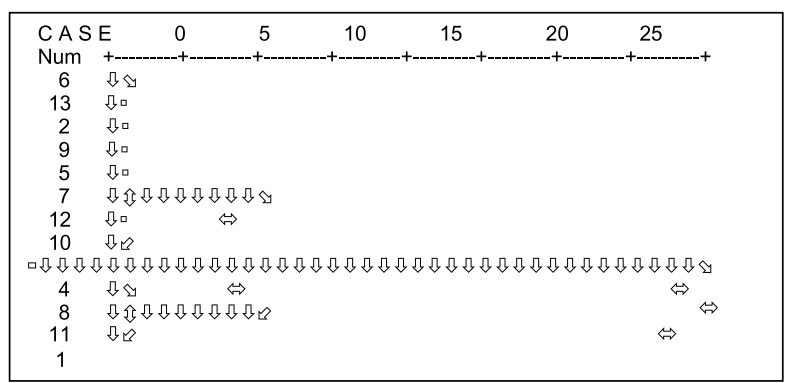

Fig. 2 Hierarchical clustering result

Supposing the linking level is 5 , then effect factors on rearend accidents are classified into three types by Fig. 2 .
(3) Result analysis

By chart analysis in Fig. 1, three types are acquired. The first is fatigue driving and over-speeding and the second includes environmental factor, unsafe following, and truck overload.

With clustering analysis, three types are also acquired. The first is fatigue driving and over-speeding and the second is vehicle factors, unsafe following distance, and truck overload. Then the third includes improper brake, passenger overloading, illegal overtaking, environmental factors, drunk driving, illegal lane-change and pavement conditions.

The analysis result indicates their consistency. To the comprehensive analysis, the outstanding five effect factors are chosen as fatigue driving, over-speeding, vehicle factors, unsafe following distance and vehicle overload.

\subsection{Effect factor of stationary vehicle collision}

Using charts and cluster analysis methods to choose the effect factors behind the accident, then the main effect factors can be selected.

(1) Chart method

Effect factors acquired by principal component analysis are sorted according to size, then the evaluation index chart is drawn, as shown in Fig. 3.

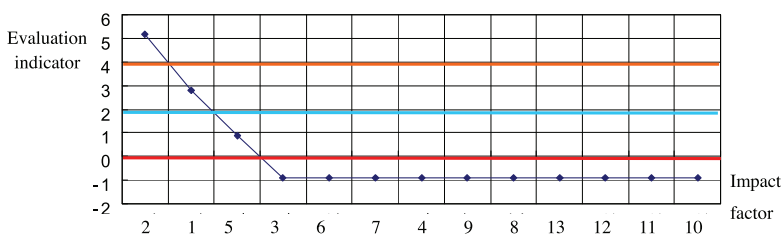

Fig. 3 Effect factor evaluation on stationary vehicle collision on freeway

From Fig. 1, design elements are divided into four types according to the curve trend, then 4,2 and 0 are chosen as thresholds.

(2) Clustering analysis

With SPSS, Fig. 4 shows the result of clustering analysis.

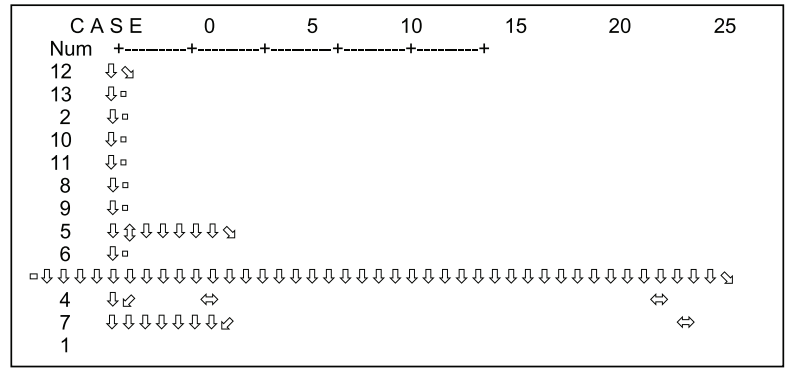

Fig. 4. Hierarchical clustering result 
Supposing the linking level is 5 , then effect factors on rearend accidents are classified into four types by Fig. 4 .

(3) Analysis result

By chart analysis in Fig. 3, four levels are acquired. The first is trunk driving, the second is over-speeding, the third is overcrowd, and the forth includes fatigue driving, illegal overtaking, illegal parking, truck overload, illegal lane-change, unsafe following, environmental factors, pavement, vehicle effect, and brake misconduct.

With clustering analysis, four types are also acquired. The first is over-speeding driving, the second is fatigue driving, the third is illegal parking and the forth includes improper brake, passenger overloading, illegal overtaking, environmental factors, drunk driving, illegal lane-change and pavement conditions, vehicle factors, unsafe following distance and truck overload. The analysis result indicates their consistency. To the comprehensive analysis, the outstanding three effect factors are chosen as over-speeding, fatigue driving and illegal parking.

\section{Conclusion}

Evaluation indicators are investigated to analyze the effect factors on rear-end accident and stationary vehicle collision by the principal component analysis method. Our preliminary data shows that based on the methodology integrated with PCA algorithm, the accident features could be effectively extracted and the effect factors can be classified with a promising accuracy. By chart comparison and clustering analysis, the main effect factors on rear-end accident on freeway are identified as fatigue driving, over-speeding, environmental factor, unsafe following, and truck overload. However, trunk driving, over-speeding, overcrowd, fatigue driving and illegal overtaking are detected as the main effect factors on stationary vehicle collision on freeway. Further work will consider other feature extraction techniques combined with SVM model.

\section{References}

[1] HAMADA, M.: Analysis of Traffic Accident Trends in Japan and Predictions for the Future. Review of Automotive Engineering, 2006, 27 (1): $145-150$

[2] NAGAI, M.: Enhancing Safety and Security by Incident Analysis Using Drive Recorders. Review of Automotive Engineering, 2006, 27 (1): $9-15$

[3] BUTTON, N. P, REILLY P. M.: Uncertainty in Incident Rates for Trucks Carrying Dangerous Goods, Accident Analysis and Prevention, 2000, 32 (6): 797-804

[4] COMPTON, R. P.: Crash Risk of Alcohol Impaired Driving, Proc. $16^{\text {th }}$ Intern. Conference on Alcohol, Drugs and Traffic Safety, Aug. 4-9, 2002, Montreal, Canada, 975-983

[5] HORWOOD, L. J., FERGUSSON, D. M.: Drunk Driving and Traffic Accidents in Young People, Accident Analysis and Prevention, 2000, 32 (6): 805-814

[6] DAVIS, G. A, SWENSON, T.: Collective Responsibility for Freeway Rear-ending Accidents?, An Application of Probabilistic Causal Models, Accident Analysis and Prevention, 2006, 38 (4): 728-736

[7] GARCIA, A, MARTIN, A, PAEZ, J.: Analysis of the Driver's Workplace in Coaches Related to Passive Safety, Intern. Journal of Vehicle Design, 2006, 42 (1-2): 134-153

[8] NEYENS, D. M, BOYLE, LINDA, N. G.: The Effect of Distractions on the Crash Types of Teenage Drivers, Accident Analysis and Prevention, 2007, 39 (1): 206-212

[9] MORI, Y., MIZOHATA, M.: Characteristics of Older Road Users and Their Effect on Road Safety, Accident Analysis and Prevention, 1995, 27 (3): 391. 